\title{
Possibilidades de objetivação dos princípios didáticos que embasam uma Aprendizagem Desenvolvimental para a organização de um currículo na área da Matemática
}

\author{
Possibilities of objectifying the didactic principles that base \\ Learning Development for an organization of a curriculum in the \\ Mathematics fields
}

\author{
William Casagrande Candiotto ${ }^{1}$ \\ Iuri Kieslarck Spacek ${ }^{2}$ \\ Eloir Fátima Mondardo Cardoso ${ }^{3}$
}

\section{RESUMO}

As pesquisas sobre a organização da Aprendizagem Desenvolvimental, em especial as realizadas no sistema Elkonin-Davidov-Repkin, evidenciam o desenvolvimento do pensamento teórico pelos estudantes. O pressuposto é que essa organização subsidia o desenvolvimento da práxis pedagógica para a formação omnilateral. Com esse pressuposto, foi realizado uma pesquisa ${ }^{4}$, na modalidade teórica, que investigou as possibilidades de objetivação dos princípios didáticos que embasam uma Aprendizagem Desenvolvimental para a organização de um currículo de Matemática. O referido objetivo surgiu do questionamento: como se estrutura um currículo na área da Matemática com base nos princípios didáticos que fundamentam a Aprendizagem Desenvolvimental? Visando buscar elementos que contribuam para responder ao questionamento, fundamentamo-nos nas obras dos autores que elaboraram o sistema ElkoninDavidov-Repkin, com foco nos aspectos didáticometodológicos desenvolvidos. Entre eles, destacamos os princípios didáticos (novo conteúdo,
\end{abstract}

\begin{abstract}
The research on the organization of Developmental Learning, especially those carried out in the Elkonin-Davidov-Repkin system, confirm the development of theoretical thinking by students. The assumption is that this organization supports the effective of pedagogical praxis for an omni lateral formation of those sought. With this assumption, was carried out a research, in the theoretical modality, investigated the possibilities of objectifying the didactic principles that support a Developmental Learning for the organization of a Mathematical curriculum guidelines. This objective arose from the question: How is a school curriculum guideline in the area of Mathematics structured from the didactic principles that underlie Learning Development? In order to search for elements that contribute to answer to this question, we are based on the works of the authors who elaborated of the Elkonin-DavidovRepkin system, with greater attention to the didactic-methodological aspects developed. Among them, we highlighted the didactic principles (new content, education that develops, activity and
\end{abstract}

${ }_{1}^{1}$ Centro Universitário Barriga Verde - Unibave, Brasil. Orcid: https://orcid.org/0000-0002-09555577. E-mail: williamcasagrande@hotmail.com.

2 Instituto Federal de Educação, Ciência e Tecnologia de Santa Catarina - IFSC, Brasil. Orcid: https://orcid.org/0000-0002-8785-9912. E-mail: iuri.spacek@ifsc.edu.br.

${ }^{3}$ Universidade do Extremo Sul Catarinense - Unesc, Brasil. Orcid: https://orcid.org/0000-00033489-8771. E-mail: efm@unesc.net.

${ }^{4} \mathrm{O}$ presente trabalho foi realizado com o apoio da Coordenação de Aperfeiçoamento de Pessoal de Nível Superior - Brasil (CAPES) - Código de Financiamento 001. 
educação que desenvolve, atividade e caráter objetal), idealizados por Davydov (2017), considerados fios condutores de nossa análise. Como resultados da investigação, indicamos possibilidades e limitações na elaboração de um currículo, como: forma de seleção dos conceitos, considerando a finalidade da formação do pensamento teórico; conteúdo dos conceitos e sua objetivação na organização do ensino, pautada na sua gênese e no seu desenvolvimento, evidenciada na identificação do fundamento geneticamente inicial e objetivada nos sistemas de tarefas; bem como envolvimento dos sujeitos que objetivam o currículo. Esta compreensão de currículo implica a investigação de novos modos de sua efetivação para a constituição de uma educação para o futuro, os quais se destacam aqueles embasados na Aprendizagem Desenvolvimental.

Palavras-chave:

Aprendizagem Princípios didáticos. object character), idealized by Davydov (2017), considered here guiding threads of our analysis. As a result of the investigation, we indicate possibilities and limitations in the elaboration of a school curriculum guidelines, which are: the form of selection of concepts, considering the form of formation of theoretical thinking aimed; contents of concepts and their goal in the teaching organization, based on their genesis and development, evidenced in the identification of their genetically initial foundation and objectified in the task systems; and those involved in the objects that the School Curriculum aims at. This understanding of the curriculum implies the investigation of new ways of realizing the constitution of an education for the future, which stand out those based on Developmental Learning.

Keywords: Developmental Learning. School Curriculum. Mathematic. Didactic Principals.

\section{Introdução}

A pretensão de discutir a temática que envolve o currículo surgiu da necessidade de compreender sua organização, na área da Matemática, com base nos princípios didáticos que fundamentam uma Aprendizagem Desenvolvimental, a saber, aquela que se objetiva no sistema Elkonin-Davidov-Repkin ${ }^{5}$.

O pressuposto inicial partiu do argumento de que tal organização curricular auxilia no desenvolvimento da práxis pedagógica com vistas à formação integral dos estudantes. Neste âmbito, busca-se discutir as possibilidades de objetivação dos princípios didáticos que embasam a Aprendizagem Desenvolvimental de forma a dar subsídio para responder ao problema traduzido no seguinte questionamento: como se estrutura a organização de um currículo na área da Matemática com base nos princípios didáticos que embasam a Aprendizagem Desenvolvimental?

\footnotetext{
${ }^{5}$ Segundo PUENTES (2019), existem diversos sistemas que possuem a concepção de Aprendizagem Desenvolvimental, ou seja, que se embasam em uma mesma matriz teórica, aquela desenvolvida por Vigotski, Rubinstein e Leontiev. Dentre eles, o autor destaca o sistema zankoviano, o sistema Galperin-Talízina e o sistema Elkonin-Davidov-Repkin. Cientes dessa questão e das diferenças entre os sistemas, no presente artigo, optou-se pelo termo Aprendizagem Desenvolvimental sempre que se referir ao sistema Elkonin-Davidov-Repkin.
} 
Os princípios (novo conteúdo, educação que desenvolve, atividade e caráter objetal), elaborados por Davydov (2017), para superar aqueles que ele considera os princípios do ensino tradicional (caráter sucessivo da aprendizagem, acessibilidade, caráter consciente e caráter visual, direto ou intuitivo), desenharam as linhas mestras de nossa análise.

Os princípios podem contribuir para o desenvolvimento de uma educação que forme o homem contemporâneo, isto é, aquele que elabora seu futuro à luz de sua história. Assim, produz-se uma educação para o futuro, qual seja, aquela que compreende as ações humanas como uma unidade entre as esferas individuais e sociais, promove uma consciência de classe e projeta ações revolucionárias com o propósito de transformação do modo hodierno de produção da vida humana (SAVIANI, 2010). Levando isso em consideração, apresentamos possibilidades e limitações na elaboração de um currículo nessa perspectiva, com uma análise que valoriza aspectos como a participação da comunidade escolar, tendo como referência o período em que se inicia no primeiro ano do Ensino Fundamental.

Para tanto, a discussão parte de uma exposição sobre as concepções de currículo ao longo da história do desenvolvimento da educação com a intenção de evidenciar seu caráter sócio-histórico. Em seguida, são apresentados os princípios didáticos que norteiam uma organização curricular, com base na Aprendizagem Desenvolvimental, bem como que objetive o currículo com vistas à formação de indivíduos omnilaterais. $\mathrm{Na}$ sequência, são sugeridas as possibilidades de encontrar indicativos de estruturação de uma organização curricular na área da Matemática com base na Aprendizagem Desenvolvimental.

\section{Concepções de currículo e sua relação com a Matemática}

A temática que envolve o currículo apresenta vasto debate no que diz respeito a sua gênese e seu desenvolvimento. Ele possui importância na estruturação da práxis pedagógica tanto quanto o planejamento e a avaliação. Nesse contexto, "a avaliação da atividade pedagógica é que possibilita a avaliação do currículo e que imprime movimento a este. É esse movimento que nos permite assumir o currículo como orientador e orientado pela atividade pedagógica que o 
concretiza" (MOURA, 2017, p. 125, itálico do autor). Toda essa organização, numa perspectiva crítica, subsidia o desenvolvimento da referida práxis, com vistas à formação omnilateral dos indivíduos.

Segundo Lundgren (1997), podemos estabelecer o significado de currículo a partir de três pilares: a) uma seleção de conhecimentos e habilidades que a educação escolar precisa desenvolver nos estudantes; b) a organização desses conhecimentos e dessas habilidades e; c) sua metodologia no que diz respeito às sequências de ensino, condução, avaliação etc.

Esse significado de currículo, pensado no âmbito da Matemática, está inscrito na esfera da educação escolar e apresenta-se como a expressão de todo o seu processo de constituição. A escolha de conceitos matemáticos e metodologias está intimamente ligada às concepções pedagógicas advogadas por aqueles que fazem frente à elaboração curricular. Subjacente a esse processo, também podemos observar as concepções de mundo, homem e sociedade que fundamentam sua elaboração. Desse modo, o currículo escolar se expressa como um reflexo do modo de organização social historicamente situado e economicamente determinado.

A determinação econômica socialmente estabelecida na organização curricular pode ser observada nos documentos oficiais desenvolvidos pelos órgãos estatais responsáveis pela regulação da educação formal no País. Podemos citar a BNCC (BRASIL, 2017, p. 8), que sugere o desenvolvimento de competências, entendidas como "[...] mobilização de conhecimentos [...], habilidades [...], atitudes e valores para resolver demandas complexas da vida cotidiana, do pleno exercício da cidadania e do mundo do trabalho".

Esse documento, bem como os outros editados com a finalidade de regular a educação escolar brasileira, tem influências sociais, políticas e econômicas quanto ao desenvolvimento de uma educação que promova a manutenção do status quo. Nesse contexto, cabe aos professores de Matemática, que visam uma educação promotora do desenvolvimento omnilateral humano, a tarefa de investigar as bases teóricas que fundamentam o currículo, a fim de identificar as formas mais eficientes de combate às teorias curriculares com viés reacionário.

Nessa direção, Sacristán (2000, p. 15-16) afirma que o currículo 
É uma prática, expressão, da função socializadora e cultural que determinada instituição tem, que reagrupa em torno dele uma série de subsistemas ou práticas diversas, entre as quais se encontra a prática pedagógica desenvolvida em instituições escolares que comumente chamamos ensino. [...] O currículo, como projeto baseado num plano construído e ordenado, relaciona a conexão entre determinados princípios e uma realização dos mesmos, algo que se há de comprovar e que nessa expressão prática concretiza seu valor.

O autor enfatiza a função socializadora e cultural que as instituições apresentam na organização de seu currículo. Sua estruturação toma por base as práticas desenvolvidas no processo e seus princípios pedagógicos quando tratam de instituições escolares. Fica evidente na definição do autor a sua postura dialógica que envolve estudantes, professores e outros elementos constitutivos dessa organização. Desse modo, o caminho de desenvolvimento de um currículo integral toma como critério de verdade a prática, uma vez que tangencia aspectos como a participação da comunidade escolar, com o intuito de que tal elaboração não se objetive em um mero documento formal.

Quando a elaboração de um currículo é abordada, faz-se necessário conhecer as concepções que as fundamentam teoricamente, como dito anteriormente, em especial no que diz respeito ao ensino de Matemática. Peres (2015) apresenta uma caracterização sobre a processualidade histórico-teórica das teorias curriculares ao longo da história do desenvolvimento da educação, desde a Grécia Antiga.

A autora expõe a seguinte classificação: código curricular clássico, código curricular realista, código curricular moral, código curricular racional, teoria curricular prática, código curricular invisível, teoria curricular crítica e teoria curricular pós-crítica. Tal caracterização teórica se expressa no currículo de Matemática ao longo da história do desenvolvimento da educação escolar e, dialeticamente, sofre influências do processo de ensino desta ciência.

As influências sociais, políticas e econômicas que o currículo de Matemática sofreu, em especial no século passado, são de interesse para a presente pesquisa. Uma dessas influências diz respeito às reformas curriculares que, como aludido anteriormente, apresentam elementos sociais historicamente situados e economicamente determinados. Segundo Pires (2008, p. 15), 
No Brasil, a trajetória das reformas curriculares evidencia dois importantes marcos, na primeira metade do século XX. A chamada reforma Francisco Campos, em 1931 e a reforma Gustavo Capanema, em 1942. Na primeira, [...] Euclides Roxo teve papel importante, ao propor a unificação dos campos matemáticos Álgebra, Aritmética e Geometria - numa única disciplina, a Matemática, com a finalidade de abordá-los de forma articulada interrelacionada, uma vez que anteriormente cada um deles era estudado como disciplina independente.

Esse exemplo apresenta elementos que evidenciam a influência das concepções acerca do objeto da Matemática na organização curricular desta disciplina escolar. Isso reforça a hipótese de que a compreensão dos conceitos matemáticos possui prioridade ontológica em relação à organização de seu ensino, ou seja, o método (compreendido como uma concepção) é determinante em relação às metodologias de ensino desta ciência.

Além da organização do ensino e do método, apresentam-se no processo de organização curricular outros elementos, por exemplo, o que ensinar. Estas definições, via de regra, apresentam caracterizações morais, como se observa no chamado código curricular moral. Ele surgiu no período histórico em que houve um deslocamento da relação sociedade versus Igreja para a relação sociedade versus Estado. Nesse ínterim, o centro de gravidade do currículo passou a ser a educação para a cidadania, porém o objetivo principal consistia em estabelecer os direitos e deveres dos indivíduos em relação ao Estado burguês. "A questão em voga estava relacionada com o que ensinar, pois, além dos conhecimentos a serem transmitidos, uma nova ideologia precisava ser apropriada, qual seja, a ideologia da classe burguesa" (PERES, 2015, p. 132).

Outro exemplo dessas influências das concepções acerca da Matemática nas elaborações do currículo é o Movimento da Matemática Moderna (MMM), bem como movimentos político-econômicos que buscavam sua superação. Segundo Pires (2008, p. 15-16),

Na segunda metade do século XX, três períodos marcantes podem ser identificados: o primeiro, caracterizado pela influência do Movimento Matemática Moderna (de 1965 a 1980); o segundo, 
caracterizado por reformas que buscavam se contrapor ao ideário do Movimento Matemática Moderna (de 1980 a 1994) e lideradas por Secretarias Estaduais e Municipais de Ensino; o terceiro, organizado em nível nacional e consubstanciado num documento divulgado ao conjunto das escolas brasileiras, denominado Parâmetros Curriculares Nacionais (a partir de 1995).

Muitos desses movimentos se autodenominam críticos e, mais recentemente, surgiram denominações ditas pós-críticas. No âmbito dessas caracterizações, há que se compreender em qual campo teórico-metodológico de constituição de um currículo estão assentados tais movimentos.

A teoria curricular crítica surgiu em contraposição às demais teorias curriculares, com o intuito de estabelecer um caráter dialético e emancipador na análise da estrutura escolar, no que tange às determinações do currículo. Segundo Kemmis (1993), essa teoria se apresenta em três princípios: raciocínio dialético, interesse emancipatório e crítica ideológica. Nesse viés, a teoria curricular crítica lança luz aos “[...] processos de reprodução social, econômica e cultural dominantes, condições que contribuem para reprodução e perpetuação das desigualdades sociais por intermédio da educação [...]" (PERES, 2015, p. 151).

Já a teoria curricular pós-crítica foi de encontro aos padrões de racionalidade estabelecidos pela Modernidade. O centro de gravidade dos debates realizados na teoria curricular crítica se alterou e "[...] as abordagens que eram organizadas ao redor dos conceitos de poder, ideologia, reprodução social, emancipação, entre outros, começam a ser substituídas por cultura, identidade, raça, gênero, sexualidade, discurso, linguagem e subjetividade" (PERES, 2015, p. 153).

Essa breve incursão na processualidade histórico-teórica das teorias curriculares pode contribuir na elaboração de um currículo de Matemática e sua objetivação que apresente um itinerário de forma clara e esboce os fundamentos de sua concepção teórico-metodológica. A possibilidade de marcar teoricamente a concepção de um currículo de Matemática pode também contribuir para a objetivação de princípios didáticos que estão na base de sua organização. Assim, ao fazer essas alusões às teorias que fundamentaram historicamente o currículo, tem- 
se a possibilidade de propor uma postura crítica no que diz respeito a sua elaboração sobre uma base materialista dialética.

Um currículo de Matemática pode ser pensado baseado nos princípios didáticos e práticas pedagógicas que alicerçam as concepções de educação e, por conseguinte, de homem, mundo e sociedade. Destarte, entender como a teoria da Aprendizagem Desenvolvimental pode embasar a elaboração de um currículo, em especial na área de Matemática, tornou-se elemento basilar desta pesquisa.

O objetivo deste artigo é, portanto, discutir as possibilidades de objetivação dos princípios didáticos que embasam a Aprendizagem Desenvolvimental para a organização de um currículo na área da Matemática. Nesse sentido, compreender alguns elementos, como os apresentados anteriormente, cria subsídios para pensar os princípios didáticos que norteiam a organização curricular da área da Matemática.

\section{Princípios didáticos que norteiam a organização curricular com base na Aprendizagem Desenvolvimental}

O presente entendimento para a formulação de um currículo de Matemática vai além da organização dos conceitos a serem desenvolvidos na disciplina. A estruturação das disciplinas escolares deve propiciar a formação mais ampla, qual seja, o desenvolvimento integral dos estudantes no nível mais alto de consciência. Com relação às disciplinas escolares, Davídov (1988, p. 99, tradução nossa) afirma que o "[...] conteúdo destas e os meios para implantá-las no processo didático-educacional determinam essencialmente o tipo de consciência e pensamento que se forma nos escolares [...]”.

Para Davídov (1988), o processo didático educativo escolar que possibilita aos estudantes a assimilação do conteúdo teórico é o mais eficaz para o desenvolvimento da consciência social. Sendo assim, é importante destacar que o sistema Elkonin-Davidov-Repkin, por meio das formulações teórico-metodológicas, fornece subsídios para pensar a elaboração e objetivação de um currículo como um movimento que tem uma finalidade específica a qual se consubstancia na formação das máximas capacidades desenvolvidas pelo gênero humano nos indivíduos, ou seja, na formação do homem contemporâneo (SAVIANI, 2010). 
Para Davydov (1982, p. 7, negrito no original, tradução nossa), uma das principais metas da escola é

[...] a formação de um nível de pensamento mais alto, que aquele que serve de orientação do sistema tradicional de ensino. Adiantamos a tese de que este tem que ser o nível do pensamento científico-teórico contemporâneo, cujas regularidades revela a dialética materialista como lógica e teoria do conhecimento.

Uma formação que almeja superar um ensino com base empírica, própria do ensino tradicional, pressupõe um novo modo de organização da aprendizagem que coloque o sujeito em Atividade de Estudo e que tenha como objetivo a apropriação dos conhecimentos teóricos e a formação de modos gerais de ação com eles (DAVÍDOV, 1988). Assim, uma ampla gama de fatores deve ser considerada na prática educativa intencional, a saber: as questões filosófico-sociológicas sobre a natureza do processo criativo e assimilativo da cultura em suas transformações históricas; a estrutura lógica do pensamento científico contemporâneo, bem como seus métodos de investigação, exposição e de seu estudo; aspecto psicológico do desenvolvimento da atividade mental, considerando-se as formas genéricas da relação entre pensamento e atividade; o problema pedagógico da direção do processo de assimilação da cultura social pelo indivíduo, que pressupõe a elaboração de uma "tecnologia” concreta de ensino (DAVYDOV, 1982).

Desse modo, pensar um currículo na perspectiva da Aprendizagem Desenvolvimental e, mais especificamente, com base no sistema Elkonin-DavidovRepkin, passa pela consideração desses aspectos, uma vez que sua inter-relação permite, segundo Davydov (1982, p. 6), “[...] resolver eficaz e consequentemente o problema de harmonizar o conteúdo e os métodos de ensino com os progressos científico-técnicos contemporâneos".

A elaboração de um currículo com bases nos pressupostos do sistema Elkonin-Davidov-Repkin é um movimento constante que engloba diferentes fatores envolvidos, sejam eles a seleção do sistema de conceitos a serem apropriados, o estabelecimento das tarefas principais em cada disciplina, o processo de organização da aprendizagem, o movimento de formação dos professores e a sua mobilização para a objetivação do currículo, como indica Moura (2017). Para lançar 
luz sobre alguns dos princípios essenciais a fim de desenvolver um currículo nessa perspectiva, segue uma exposição acerca dos princípios didáticos elaborados por Davydov (2017), contrapostos aos princípios didáticos tradicionais. É importante destacar que as características apontadas por Davydov (2017), como sendo tradicionais, têm sido identificadas no modo de organização do ensino no Brasil, conforme constataram Rosa (2012) e Hobold (2014).

Davydov (2017) aponta que a educação escolar, na União das Repúblicas Socialistas Soviéticas (URSS), buscava, por meio de pesquisas, substituir a escola tradicional, que não mais respondia às exigências da revolução técnicocientífica. Para o autor, a escola tradicional se formou a partir do nascimento da produção capitalista com o objetivo de solidificar e manter seus princípios, ou seja, "[...] formar as capacidades psíquicas do homem no alcance desses objetivos" (DAVYDOV, 2017, p. 211).

Como mencionado, a crítica à escola, a qual se orienta nos princípios didáticos tradicionais, funda-se no tipo de pensamento formado nos estudantes que por ela passam, o pensamento empírico, o qual orienta os afazeres cotidianos. Esses princípios são insuficientes para a apropriação da ciência atual, para o desenvolvimento da criatividade e de um conteúdo que possibilite a compreensão das contradições de uma sociedade fundada na exploração de uma classe por outra.

Assim, como diz Moura (2017, p. 100), consideramos que uma proposta curricular é "[...] um modelo de estruturação do conhecimento escolar considerado essencial para uma determinada sociedade".

Davídov e Slobódchikov (1991) consideravam indispensável analisar criticamente os princípios pedagógicos que embasavam a organização do ensino na escola soviética, uma vez que os entendiam como predominantemente tradicional. Os princípios didáticos que regem o ensino tradicional, segundo Davydov (2017), denominam-se o caráter sucessivo da aprendizagem; a acessibilidade; o caráter consciente e o visual, direto ou intuitivo do ensino. Esses, segundo o autor, devem ser substituídos, respectivamente, pelos princípios do caráter novo dos conhecimentos; da educação que desenvolve; da atividade e do caráter objetal. 
Conforme Davídov e Slobódchikov (1991), esses seriam os princípios de um novo pensamento pedagógico ou da pedagogia colaborativa.

O caráter sucessivo da aprendizagem se caracteriza por uma estruturação das disciplinas escolares que mantém relação com o conhecimento cotidiano, ou seja, não se altera o conteúdo dos conhecimentos com o ingresso da criança na escola. Isso se estende para além dos primeiros anos escolares, percorrendo toda a Educação Básica. Na disciplina de Matemática, é viva a elaboração do conceito de número com base nesse princípio, que se evidencia no conceito de número natural pela contagem discreta de objetos soltos desde o primeiro ano escolar e que se mantém até o Ensino Médio.

O entendimento é que a complexidade ocorre pela justaposição dos conjuntos numéricos do mesmo modo que se constituiu historicamente - natural, racional, irracional, real e relativos (CARAÇA, 2003). Como afirma Davydov (2017, p. 214), “[...] não se diferenciam, de maneira clara, as particularidades e a especificidade da etapa seguinte na aquisição de conhecimentos em comparação com a precedente". Nesse sentido, o caráter científico do conceito de número é compreendido de forma empírica. Não há mudança no conteúdo e na forma do ensino quando se passa de um nível ao outro ou mesmo de um ano para o outro. $\mathrm{O}$ que caracteriza a complexidade é o aumento quantitativo do volume de conhecimentos que os estudantes recebem. Esse modo de pensar que caracteriza o princípio da sucessão de conhecimentos não diferencia qualitativamente os conceitos cotidianos dos científicos (DAVÍDOV; SLOBÓDCHIKOV, 1991).

A substituição do princípio do caráter sucessivo, de acordo com Davydov (2017), pressupõe a verdadeira significação dialética do caráter científico do conceito que se fundamenta no caráter novo dos conhecimentos. Desse modo, não são negados a sucessão e o vínculo dos conhecimentos, mas o processo de ensino se organiza de modo que o estudante perceba a diferença daquilo que se apropriou anteriormente. Isso significa que as etapas que caracterizam o ensino se diferenciam tanto pelo conteúdo quanto pelos procedimentos próprios da Aprendizagem Desenvolvimental. Os anos iniciais, nesse princípio, caracterizam- 
se pelo início da formação das crianças, por meio da Atividade de Estudo, cuja possibilidade de aprendizagem se dá pela assimilação dos conceitos científicos.

Nas etapas subsequentes, conforme Davydov (2017, p. 218),

[...] a forma e o conteúdo dos conhecimentos e as condições de sua assimilação devem ter uma organização qualitativa diferente dos níveis anteriores. São as diferenças qualitativas - e não as quantitativas -, nas diversas etapas do ensino, que devem estar na base das ideias dos organizadores do ensino e psicólogos ocupados na estruturação do sistema total de ensino médio (a conexão do qualitativamente diferente é a verdadeira dialética do desenvolvimento e também a dialética de sua teoria).

Outro princípio do ensino tradicional é o da acessibilidade. Nele a organização das disciplinas escolares se caracteriza por confirmar aquilo que os estudantes são capazes de se apropriar em uma certa idade. $\mathrm{O}$ enfoque da educação escolar, em relação às aprendizagens, centra-se no empírico-utilitário e no pensamento empírico-classificador. Esse ponto de vista promove o desenvolvimento psíquico com base na Psicologia Evolutiva, que desconsidera as condições histórica, social e concreta da infância e de suas particularidades. Além disso, outro aspecto do ensino que caracteriza o referido princípio é o das possibilidades já formadas e presentes na criança (DAVYDOV, 2017). Seguir esse princípio, conforme Davydov (2017), significa subestimar as possibilidades de apropriação dos estudantes, bem como do papel que a educação exerce no desenvolvimento psíquico desses indivíduos. $\mathrm{Na}$ sua objetivação, o princípio da acessibilidade é contraditório à educação que promove o desenvolvimento.

Nesse sentido, em substituição ao princípio da acessibilidade, o novo pensamento pedagógico se estrutura pelo princípio da educação que desenvolve. Segundo Davídov e Slobódchikov (1991, p. 130, tradução nossa),

Tal ensino deve, realmente, "arrastar consigo" o desenvolvimento; deve criar nas crianças aquelas condições e premissas do desenvolvimento psíquico que podem faltar neles, mas que são, em princípio indispensáveis do ponto de vista das normas e exigências supremas da escola futura. 
O pressuposto desse princípio está na elaboração de forma ativa e compensatória, indispensável para alcançar um alto nível de desenvolvimento psíquico dos estudantes. É nesse pressuposto que encontramos a chave para o entendimento do desenvolvimento das Funções Psicológicas Superiores e, por extensão, da formação do psiquismo como um todo. Para Vigotski (2002, p. 118), “[...] o aprendizado é um aspecto necessário e universal do processo de desenvolvimento das funções psicológicas culturalmente organizadas e especificamente humanas".

Davydov (2017) aponta que um dos problemas mais difíceis, porém mais importantes para a organização da escola sob a orientação dos novos princípios, consiste em descobrir as leis da educação que exerçam influência no desenvolvimento integral dos estudantes.

O princípio do caráter consciente com base nos fundamentos do ensino tradicional encontra respaldo teórico no formalismo. Nessa concepção, o conhecimento é compreendido, primeiramente, “[...] em forma de abstrações verbais claras e sucessivamente desdobradas [...]. Em segundo lugar, cada abstração verbal deve ser correlacionada, pela criança, com uma imagem sensorial completamente definida e precisa" (DAVYDOV, 2017, p. 216).

Em contraposição ao princípio do caráter consciente, apresenta-se o da atividade. De acordo com Davídov e Slobódchikov (1991), o caráter consciente pode ser realizado se os estudantes não receberem os conhecimentos prontos pelos professores. Os autores esclarecem que o modo de organizar o ensino, consoante ao princípio da atividade, pressupõe revelar a essência que originou esses conceitos, os quais se concretizam "[...] quando as crianças efetuam aquelas transformações específicas dos objetos, graças as quais, em sua própria prática escolar, modelamse e recriam-se as propriedades internas do objeto que se convertem em conteúdo do conceito" (DAVÍDOV; SLOBÓDCHIKOV, 1991, p. 131, tradução nossa). Desse modo, o princípio da atividade na educação contribui para ultrapassar o sensualismo unilateral, o nominalismo e o associacionismo que caracterizam o ensino tradicional. Em função disso, é resolvido o problema da utilidade empírica do conhecimento. A solução de tarefas práticas é orientada por meio da apropriação 
dos conceitos científicos, que na Atividade de Estudo expressam as qualidades internas dos objetos do conhecimento.

Os atributos do princípio do caráter visual, direto ou intuitivo definem o teor empírico do conteúdo, cuja prática pedagógica se constitui em um desalento no desenvolvimento psíquico dos estudantes. Davydov (2017) considera que os adeptos desse princípio se apoiam na base sensorial dos conceitos, reduzindo-os aos conhecimentos empíricos que formam o pensamento racionalista discursivoempírico e classificador. Nessa perspectiva, são observadas e comparadas as propriedades externas do objeto, ou seja, as evidências de propriedades e qualidades que se diferenciam ou se aproximam de todo um grupo de objetos ou fenômenos. O princípio do caráter visual, ao destacar as características de um objeto ou fenômeno isolado e compará-las com os demais, direciona a generalização empírica por meio de um procedimento que se orienta do particular ao geral.

Ao princípio do caráter visual, direto ou intuitivo se opõe o princípio do caráter objetal, o qual oportuniza aos estudantes se apropriarem do conhecimento teórico. De acordo com Davydov (2017), nesse percurso, destacam-se duas características básicas. Na primeira, o pensamento do estudante se move do geral ao particular. "O geral é compreendido como conexão geneticamente inicial do sistema estudado, a qual, em seu desenvolvimento e diferenciação, gera o caráter do sistema concreto" (DAVYDOV, 2017, p. 220). As particularidades são deduzidas partindo do núcleo generalizado do conceito estudado. Desse modo, a generalização do conteúdo empírico (do particular ao geral) ocorre inversamente no conteúdo teórico (do geral ao particular). Na segunda forma de generalização, em vez de receber os conhecimentos prontos, são apresentadas aos estudantes as condições que os originaram. Para isso, é necessário que se realizem as transformações específicas dos objetos e fenômenos, reproduzindo os modelos (na forma objetal, gráfica e literal) e suas propriedades internas que se transformam no conteúdo do conceito (ROSA, 2012).

Portanto, no processo educativo, a tarefa essencial de todo um conjunto de disciplinas, não somente da Matemática, concentra-se no estudo das leis dos conhecimentos propriamente científicos. Tal fato pode ser considerado um aspecto 
geral para a elaboração de um currículo com base nos fundamentos teóricometodológicos desenvolvidos e objetivados no sistema Elkonin-Davidov-Repkin.

\section{As possibilidades de organização de um currículo com base nos princípios didáticos da Aprendizagem Desenvolvimental}

Parte-se do pressuposto de que as contribuições para o movimento de constituição e objetivação de um currículo que norteie a formação do homem contemporâneo para uma sociedade voltada ao futuro passa pelos princípios supracitados, bem como pela organização de novas práticas educativas. Assim, com base nas contribuições e indicações dos autores envolvidos na elaboração do sistema Elkonin-Davidov-Repkin, são apresentados alguns aspectos relevantes na elaboração de um currículo que tenha por base os referidos princípios. Não serão desconsiderados, no entanto, as circunstâncias atuais, nas quais as contradições geradas pelo sistema de produção capitalista têm se expandido rapidamente à maioria das esferas da vida e diminuído a margem de atuação dos sujeitos com vista à formação do homem contemporâneo para uma sociedade do futuro e não à perpetuação de um eterno presente (SAVIANI, 2010).

Nesse sentido,

A educação para o futuro expressa-se na defesa de um tipo de ensino condizente com as exigências da formação do homem contemporâneo. Não se identifica com a visão de educação para a contemporaneidade, de cunho pragmática e utilitarista, que se volta unicamente para questões imediatas. Pretende, portanto, superar a concepção que traz subjacente a ideia de que o futuro é o presente a ser perpetuado. (SAVIANI, 2010, p. 65)

Para pensar a organização de um currículo que contribua para a formação do homem contemporâneo, tendo como princípios aqueles discutidos na seção anterior, são abordados dois aspectos na sua constituição, com foco, especialmente, no ensino de Matemática. A atenção é direcionada aos aspectos relacionados ao conteúdo do currículo, bem como ao seu movimento de constituição.

No que se refere ao conteúdo das disciplinas escolares, que compõem o currículo, é necessário que, primeiramente, identifiquem-se os conceitos essenciais 
para o desenvolvimento do pensamento teórico. Ao delimitar os conceitos, eles se objetivam na forma de sistemas de tarefas principais na medida em que relacionam a finalidade de sua apropriação com as condições para atingi-la ${ }^{6}$. Essas condições, por sua vez, são determinadas se o ponto de partida for os princípios do sistema Elkonin-Davidov-Repkin, pela relação entre o histórico e o lógico.

Para compreender como isso se objetiva na proposta de aprendizagem da Matemática, cita-se as tarefas principais que proporcionam a objetivação dessa aprendizagem nos anos iniciais de escolarização (DAVÍDOV, 1988). Conforme Davídov (1988), no período inicial de escolarização, é preciso buscar uma compreensão do conceito de número real. Para tal intento, o autor elabora um sistema de tarefas principais, as quais, segundo Davídov (1988, p. 209), são:

1) introdução dos alunos na esfera das relações entre as grandezas: formação do conceito abstrato de grandeza matemática; 2) demonstração às crianças da relação de multiplicidade das grandezas como forma geral do número: formação do conceito abstrato de número e da compreensão da inter-relação fundamental entre seus componentes [...];

3) introdução sucessiva dos escolares em áreas dos diferentes tipos particulares de números (naturais, racionais, inteiros): formação dos conceitos sobre estes números como uma das manifestações da relação múltipla geral das grandezas em determinadas condições concretas;

4) demonstração aos alunos do caráter unívoco da estrutura da operação matemática [...]: formação da compreensão sobre a interrelação dos elementos nas ações aritméticas fundamentais.

Nesse sistema de tarefas, é possível perceber que, para se apropriar do conceito de número real, Davídov (1988) considera necessária uma parte introdutória em que se assimila o fundamento geneticamente inicial o qual permitirá deduzir, posteriormente, os demais tipos de números reais. Esse fundamento se encontra no conceito de grandeza. Conforme Davídov (1988, p. 208), a “[...] assimilação da ideia básica da concepção de número real deve começar pelo domínio do conceito de grandeza e o estudo de suas principais propriedades.”

\footnotetext{
${ }^{6}$ Segundo Davídov (1988, p. 31), a tarefa é “[...] a unidade da finalidade e das condições”.
} 
A forma de escolha dos conceitos principais que comporão as disciplinas escolares é um aspecto essencial a ser considerado na elaboração de um currículo com base na Aprendizagem Desenvolvimental. Essa seleção, além de ter implícito o movimento que se desdobrará no seu ensino, apresenta indícios do processo de gênese e constituição dos conceitos. A escolha dos conceitos principais e de seus fundamentos geneticamente iniciais evidencia a relação dialética entre o produto e seu desenvolvimento, ou seja, a relação histórica e lógica.

Considerar essa relação significa entender que os conhecimentos surgem de necessidades humanas historicamente situadas, a fim de garantir a reprodução dos indivíduos e, por conseguinte, a constante reprodução do gênero humano. $\mathrm{O}$ aperfeiçoamento dos instrumentos como extensão das habilidades corpóreas do ser humano e potencializador de suas possibilidades de transformação da natureza, bem como a apreensão de suas legalidades no processo de trabalho, passam a ser fundamentais para a reprodução do ser humano.

Nesse sentido, torna-se necessária a apreensão das legalidades da natureza e a sua socialização, o que gera a necessidade de comunicação, assim como o surgimento de signos e símbolos que expandam os limites de atuação do ser humano. O processo de apreensão das legalidades da natureza, segundo Prado Júnior (1963), começa a se constituir pela identificação, ou seja, pela conceituação qualitativa do universo. No entanto, o movimento progressivo de apreensão do real torna necessário um processo de diferenciação de aspectos dentro de uma mesma qualidade, isto é, a quantidade. Nesse sentido, conforme Prado Júnior (1963), a quantidade tem um papel de subqualidade. Aqui reside “[...] o ponto de partida da conceituação quantitativa, que não consiste senão naquela conceptualização de diferenças de uma mesma qualidade" (PRADO JÚNIOR, 1963, p. 199, itálicos no original). Desse modo, para o autor, a qualidade tem função e gênese similar à da discriminação qualitativa, ou melhor, possui a função de identificação, tendo como traço diferenciador a característica de ser realizada no interior de uma mesma qualidade. Essa discriminação é, portanto, a necessidade que move o ser humano em direção à elaboração do conceito de grandeza. Ao mesmo tempo, segundo Prado 
Júnior (1963), essa também é uma das necessidades que caracterizaram a formação do pensamento matemático.

O caráter relacional da conceituação matemática emerge do conceito de grandeza, que é considerado por Prado Junior (1963, p. 200) como “objeto próprio originário" de dita conceituação, uma vez que, no processo de identificação, há a necessidade de estabelecer relações comparativas, começando pela caracterização segundo a intensidade (PRADO JUNIOR, 1963).

Desse modo, é possível perceber que a

noção de grandeza deriva dêsse [sic] dado intuitivo de intensidade, e se caracteriza logo que em tal intuição se distinguem direções: para mais e para menos. [...] Assim, se considerarmos por exemplo uma superfície de água, depois de a identificarmos qualitativamente como "água", passaremos imediatamente depois a considerar a "intensidade" daquela qualidade (ou complexo de qualidades), que no caso seria seu volume ou extensão superficial, dando assim mais um passo no processo de identificação: será uma simples poça, um lago, um mar... (PRADO JÚNIOR, 1963, p. 200, itálico no original).

Na organização do ensino proposta pelo sistema Elkonin-Davidov-Repkin, conforme exposto por Rosa (2012), é possível perceber como esse movimento inicial de comparação é desenvolvido nas tarefas propostas aos estudantes. No trabalho da autora, fica explícito que as tarefas apresentadas nos livros dos primeiros anos de escolarização, no referido sistema, apresentam essa estratégia de estabelecer relações entre grandezas. As relações são elaboradas com base na comparação estabelecida entre figuras ou objetos, seguida de modelação como uma forma de generalização dessas relações.

Para Davídov (1988, p. 208, tradução nossa),

O conceito de grandeza está vinculado com as relações "igual", "maior", "menor". A multiplicidade de quaisquer objetos se converte em grandeza quando se estabelecem os critérios que permitem determinar se $A$ é igual a $B$, maior que $B$ ou menor que $B$. (DAVÍDOV, 1988, p. 208)

Com base nesses princípios, são apresentadas tarefas particulares que têm como finalidade o surgimento da necessidade da realização de ações que tenham como fim a apropriação do conceito de número real como uma relação geral entre grandezas 
de mesma natureza (DAVÍDOV, 1988; GALPERIN; ZAPORÓZHETS; ELKONIN, 1987; ROSA, 2012). Os estudantes, nesse processo, vão se apropriando do conceito de número real partindo de sua relação mais geral, como relações entre grandezas.

Sublinhamos que a delimitação do conceito de número real como finalidade da aprendizagem da Matemática nos anos iniciais da educação escolar, bem como o estabelecimento do conceito de grandeza como sendo aquele que é o fundamento geneticamente inicial da dedução do conceito de número, pode nos ajudar a compreender os princípios e a forma geral de delimitação dos conceitos com os quais se organizaria um currículo nessa perspectiva. Assim, também nos são apresentados indícios de sua objetivação nas atividades realizadas no âmbito da educação escolar, evidenciando o princípio da atividade.

Outro aspecto a ser destacado na elaboração e objetivação do currículo é a necessária alteração do conteúdo e do método na medida em que a criança avança no processo de escolarização, destacado por Davydov (2017) no princípio do caráter novo do conhecimento. Desse modo, é necessário que se perceba a mudança em relação aos conteúdos e métodos no ensino. Conforme o autor (2017, p. 218),

Nos níveis inferiores, deve-se formar, nas crianças, a atividade de estudo [...]. Com a passagem aos níveis superiores, deve-se, pelo visto, mudar qualitativamente o conteúdo dos cursos escolares e os métodos de trabalho com eles (por exemplo, deve-se introduzir o método axiomático de exposição, o enfoque investigativo do material, etc.).

Além da seleção dos conceitos e sua abordagem, é importante focar a atenção também no que diz respeito às atividades envolvidas no processo de elaboração de um currículo. Nesse sentido, entende-se que, apesar das contribuições que se encontram nas pesquisas e produções dos autores envolvidos no sistema Elkonin-DavidovRepkin, é preciso fazer algumas ressalvas em relação ao contexto da sua obra a fim de evitar uma análise anacrônica, bem como para poder compreender os limites e as possibilidades no horizonte das condições atuais, em especial, as vigentes no Brasil.

Com tal intuito, será exposto brevemente a análise de alguns pontos do texto $L a$ enseñanza que desarrolla en la escuela del desarrollo, de Davídov e Slobódchikov (1991), uma vez que ele apresenta diversas considerações que se referem ao que os autores chamam de "nova pedagogia" ou "pedagogia da colaboração". 
É importante destacar que, no período de escrita e publicação do texto, a URSS passava por um processo de rápidas mudanças em diferentes âmbitos, incluindo as da esfera da educação. Ao se debruçarem sobre elas, os autores constataram que, "[...] junto com outras esferas da nossa vida, a instrução pública na URSS entrou em um período de perestroika radical"7 (DAVÍDOV; SLOBÓDCHIKOV, 1991, p. 118, tradução nossa). Os autores, ao que é possível constatar no restante da referida publicação, viam nesse movimento uma abertura maior para a constituição e objetivação de um "novo pensamento pedagógico" que havia "começado a formar-se" na sua "prática social" (DAVÍDOV; SLOBÓDCHIKOV, 1991, p. 119, tradução nossa).

Esse movimento de mudança tinha fundamento, segundo os autores, em alterações no sistema de administração, planejamento e controle da instrução pública, que buscavam resgatar os princípios da escola socialista, formulados no período pósrevolucionário e restabelecê-los na sua correspondência com as exigências e orientações novas de toda a vida social. (DAVÍDOV; SLOBÓDCHIKOV, 1991).

Com base nesses princípios, os autores buscaram abordar as características principais do novo pensamento pedagógico ${ }^{8}$ e destacaram entre eles a “[...] compreensão do ensino como sistema sócio-estatal [sic] que funciona agora nas condições de ampla democratização e glasnost e dirigidos por conselhos sociais em distintos níveis" (DAVÍDOV; SLOBÓDCHIKOV, 1991, p. 121, tradução nossa, itálico no original).

Nesse sistema, "[...] as instituições educativas são de autogestão [...]" e o "[...] trabalho dos professores nelas deve ser exclusivamente criativo e as escolas - tendo uma fundamentação única - devem ser muito variadas" (DAVÍDOV; SLOBÓDCHIKOV, 1991, p. 121, tradução nossa). Essa característica é bastante importante para colocar em movimento o processo de formação dos estudantes nessa perspectiva, uma vez que parte do pressuposto que os sujeitos que atuam nas

\footnotetext{
${ }^{7}$ Perestroika e glasnost foram slogans utilizados por Mikhail Gorbachev (1931 - ), secretário geral da URSS entre 1985 e 1991, como parte de sua campanha. Perestroika significava reestruturação, ligada à estrutura econômica ou política, enquanto glasnost significava liberdade relacionada à informação.

8 Além da citada no texto, Davídov e Slobódchikov (1991) enunciam como algumas características principais: a organização do ensino para a formação da personalidade criativa; a prioridade do desenvolvimento harmônico do homem; a união do trabalho com o ensino; e a gestão descentralizada.
} 
instituições escolares se coloquem em atividade. Entretanto, dadas as condições econômicas, políticas e ideológicas de nossas escolas, oriundas das formas de organização social vividas, essa característica parece estar distante de nosso contexto.

De todo modo, essa característica da chamada nova pedagogia ou pedagogia da colaboração, anunciada pelos autores, pode apresentar indícios de que a organização escolar, bem como o currículo, constituído com base em uma "fundamentação única", isto é, levando em conta os princípios pedagógicos explicitados no item anterior, assim como na concepção de educação e na finalidade educativa de formação do homem contemporâneo, devem considerar o envolvimento de diversos sujeitos, sejam eles pais, estudantes, professores, gestores e especialistas de diversas áreas ligadas à educação. Dessa maneira, pode se tornar possível a significação de um currículo que almeje e busque atingir os fins esperados, com o intuito também de formar uma personalidade harmônica, a partir do desenvolvimento de propriedades como "[...] o coletivismo e a solidariedade, o companheirismo e a civilidade, o caráter firme, o amor ao trabalho e a vontade férrea, combinados com a iniciativa e a independência" (DAVÍDOV; SLOBÓDCHIKOV, 1991, p. 120, tradução nossa).

Essa formação harmônica, na forma atual de organização social, é tendencial e encontra diversos obstáculos e limites devido às contradições geradas pela forma de reprodução social. Nesse sentido, é importante compreender essas limitações e como elas obstaculizam o processo de desenvolvimento de uma formação de indivíduos com as características supracitadas. Tal compreensão permite também desenvolver, por meio da formação do pensamento teórico, a possibilidade de apreensão dessas contradições e assim buscar as formas de superá-las.

Desse modo, a busca pela formação dessa personalidade harmônica, mesmo que de forma tendencial, passa pela formação de um currículo que seja norteado por essa finalidade, ou seja, que busque a formação do homem contemporâneo para uma sociedade do futuro e não uma sociedade do eterno presente (SAVIANI, 2010). Por esse ângulo, torna-se necessário, portanto, que o currículo não seja elaborado de maneira vertical, mas de maneira horizontal e planificada, com a participação daqueles que o vivenciam. Como experiência que se tem buscado realizar nesse 
sentido, destaca-se a descrita por Moura (2017), a qual envolveu os professores. Além dela, podem ser citados outros movimentos de elaboração do currículo que propuseram se fundamentar em diversos pontos descritos no presente artigo, como o documento do Currículo Base da Educação Infantil e do Ensino Fundamental do Território Catarinense (SANTA CATARINA, 2019) e da Proposta Curricular da Rede Municipal de Ensino de Forquilhinha (FORQUILHINHA, 2020), o qual apresenta elementosda Aprendizagem Desenvolvimental em seu texto, em especial em Matemática, apesar de seus limites, como a não organicidade ou, como diriam Davídov e Slobódchikov (1991), a falta de uma fundamentação única.

\section{Considerações finais}

Com base no debate acima exposto, tendo como norteadores os princípios didáticos desenvolvidos por Davydov (2017), bem como as análises e caracterizações de Davídov e Slobódchikov (1991) de um novo pensamento pedagógico, ou melhor, a pedagogia colaborativa, foi possível encontrar indicativos de como se estrutura a organização de um currículo na área da Matemática, as quais se embasam na Aprendizagem Desenvolvimental.

Entre esses indicativos, considera-se como relevantes a forma de seleção dos conceitos, levando em conta a finalidade de formação, pelos estudantes, do pensamento mais desenvolvido. Além disso, o conteúdo dos conceitos e a forma de objetivação da organização do ensino pautam-se na sua gênese e no seu desenvolvimento, ou seja, na relação entre o histórico e o lógico. Isso se evidencia na medida em que se identifica o fundamento geneticamente inicial dos conceitos e elaboram-se os sistemas de tarefas principais. Também é necessário prezar pela forma de envolvimento dos sujeitos que objetivam o currículo, apesar de todas as limitações as quais o contexto histórico e social impõe.

Desse modo, a compreensão de que qualquer currículo, como um elemento em movimento da esfera escolar, implica uma necessidade constante de investigação e ação para se apropriar de sua dinâmica, bem como para apontar novos modos de sua efetivação, sempre com vistas a um processo progressivo de humanização. 


\section{Referências}

BRASIL. Base Nacional Comum Curricular. Brasília: MEC, 2017. Disponível em: http://basenacionalcomum.mec.gov.br/images/BNCC_20dez_site.pdf. Acesso em: 05 jan. 2021.

CARAÇA, B. J. Conceitos fundamentais da matemática. 5. ed. Lisboa: Gradiva, 2003.

DAVÍDOV, V. V. La enseñanza escolar y el desarrollo psíquico: investigación psicológica, teórica y experimental. Moscú: Editorial Progresso, 1988.

DAVÍDOV, V. V.; SLOBÓDCHIKOV, V. I. La enseñanza que desarrolla en la escuela del desarrollo. In: MUDRIK, A. V. (org.) La educación y la enseñanza: una mirada al futuro. Trad. Marta Shuare. Moscú: Editorial Progreso, 1991, p. 118-144.

DAVYDOV, V. V. Tipos de generalización en la enseñanza. 3. ed. Habana: Editorial Pueblo y Educación, 1982.

DAVYDOV, V. V. Análise dos princípios didáticos da escola tradicional e dos possíveis princípios do ensino em um futuro próximo. In: LONGAREZI, A. M.; PUENTES, R. V. (Orgs.). Ensino Desenvolvimental: Antologia: Livro I. Uberlândia: Editora EDUFU, 2017, p. 211-223. DOI: https://doi.org/10.14393/edufu-978-85-7078-433-9.

FORQUILHINHA, Prefeitura Municipal. Proposta Curricular da Rede Municipal de Ensino de Forquilhinha. Forquilhinha: Secretaria de Educação, 2020. 313 p.

GALPERIN, P.; ZAPORÓZHETS, A.; ELKONIN, D. Los problemas de la formación de conocimientos y capacidades en los escolares y los nuevos métodos de enseñanza en la escuela. In: SHUARE, M. (Comp.). La psicologia evolutiva y pedagógica en la URSS. Moscú: Progreso, 1987, p. 300-315.

HOBOLD, E. S. F. Proposições para o ensino da tabuada com base nas lógicas formal e dialética. 2014. 199 f. Dissertação (Mestrado em Educação) Universidade do Sul de Santa Catarina, Tubarão, 2014.

KEMMIS, S. El curriculum: más allá de la teoria de la reproducción. 2. ed. Madrid, Espanha: Ediciones Morata, 1993.

LUNDGREN, U. P. Teoría del Curriculum y escolarización. 2. ed. Madrid, Espanha: Morata, 1997.

MOURA, M. O. A objetivação do currículo na atividade pedagógica. Obutchénie: R. de Didat. e Psic. Pedag., Uberlândia, MG, v.1, n.1, p. 98-128, jan./abr. 2017. DOI: http://doi.org/10.14393/OBv1n1a2017-5. 
PERES, E. S. Currículo e emancipação: uma articulação possível? 2016. 380 f. Tese (Doutorado em Educação) - Universidade Federal de Santa Catarina, Florianópolis, 2015.

PIRES, C. M. C. Educação Matemática e sua Influência no Processo de Organização e Desenvolvimento Curricular no Brasil. Bolema, Rio Claro, v. 21, n. 29, p. 13-42, 2008.

PRADO JÚNIOR, C. Dialética do Conhecimento. Tomo 1. 4. ed. São Paulo:

Brasiliense, 1963.

PUENTES, R. V. Uma nova abordagem da Teoria da Aprendizagem

Desenvolvimental. In: PUENTES, R. V.; CARDOSO, C. G. C. C.; AMORIN, P. A.

P. (Orgs.) Teoria da atividade de estudo: Contribuições de D. B. Elkonin, V. V.

Davidov e V. V. Repkin: Livro I. Curitiba: CRV, 2019, p. 31-53. DOI:

https://doi.org/10.24824/978854444104.6.

ROSA, J. E. da. Proposições de Davydov para o ensino de Matemática no primeiro ano escolar: inter-relações dos sistemas de significações numéricas. 2012. $244 \mathrm{f}$. Tese (Doutorado em Educação) - Universidade Federal do Paraná, Curitiba, 2012.

SACRISTÁN, J. G. O currículo: uma reflexão sobre a prática. 3. ed. Porto Alegre: Artmed, 2000.

SANTA CATARINA. Currículo base da educação infantil e do ensino fundamental do território catarinense. Florianópolis, SC: Secretaria do Estado da Educação, 2019. 492 p. Disponível em: http://uaw.com.br/pagflip/pdf.php?pag=portifolio\&cod=35. Acesso em: 15 jan. 2021.

SAVIANI, N. Saber Escolar, Currículo e Didática: problemas da unidade conteúdo/método no processo pedagógico. 6. ed. revista. Campinas: Autores Associados, 2010.

VIGOTSKI, L. S. A formação Social da mente. 6. ed. São Paulo: Martins Fontes, 2002. 